\title{
EXCLUSÃO E INCLUSÃO DIGITAIS E SEUS REFLEXOS NO EXERCÍCIO DE DIREITOS FUNDAMENTAIS
}

\section{DIGITAL INCLUSION AND EXCLUSION AND ITS CONSEQUENCES IN THE EXERCISE OF FUNDAMENTAL RIGHTS}

\begin{abstract}
IRINEU FRANCISCO BARRETO JUNIOR
Doutor em Ciências Sociais pela Pontifícia Universidade Católica de São Paulo (2004). Docente do Programa de Mestrado em Direito da Sociedade da Informação da FMU e Coordenador Adjunto do Curso de Direito das Faculdades Metropolitanas Unidas FMU. Analista de Projetos Pleno da Fundação Sistema Estadual de Análise de Dados Seade. Docente do Programa de Mestrado em Ciências Sociais da Universidade de Vila Velha (UVV-ES). Professor Convidado da Escola Judicial do Trabalho da Segunda Região EJUD 02. Membro Efetivo do Núcleo Docente Estruturante do Curso de Direito da FMU e do Colegiado dos Professores do Mestrado em Direito da Sociedade da Informação da FMU. Membro do Conselho Editorial da Revista Saúde e Sociedade da Faculdade de Saúde Pública da USP e da Associação Paulista de Saúde Pública. Possui experiência nas áreas de Ciências Sociais e Direito, com ênfase em Análise de Políticas Sociais, Direito na Sociedade da Informação, Análise de Dados Estatísticos, Metodologia da Pesquisa Científica, Sociologia e Didática do Ensino Superior. Palestrante e parecerista de publicações científicas.

CRISTINA BARBOSA ROdRIgUES Advogada e Professora de Direito Administrativo e Direito Tributário da Universidade Paulista - UNIP. Mestre em Direito da Sociedade da Informação pelas Faculdades Metropolitanas Unidas - FMU - SP.
\end{abstract}

\begin{abstract}
RESUMO
Este artigo aborda o fenômeno contemporâneo da exclusão digital e a possibilidade de mitigá-lo por intermédio de intervenções governamentais no formato de políticas públicas educacionais. Trata, ainda, da aplicação das Tecnologias da Informação e da Comunicação para o desenvolvimento de habilidades educacionais, como maneira de atenuar a exclusão social. Sua metodologia é fundamentada na definição conceitual da exclusão digital e na análise de políticas governamentais que vêm sendo implementadas no sentido de superá-las. Trata-se, portanto, de pesquisa conceitual teórica jurídica, com base no método analítico dedutivo. Conclui identificando a relevância da implementação de medidas para transpor barreiras e reduzir as distâncias entre aqueles que usufruem plenamente dos benefícios advindos das novas tecnologias e aqueles que são excluídos, por razões sociais, econômicas, geográficas ou demográficas. Essa diminuição, da segregação eletrônica, exige a atuação do poder público, por intermédio de políticas que enfrentem a denominada exclusão digital que aparta parcelas significativas da sociedade das benesses oferecidas pelas plataformas comunicativas da Internet.
\end{abstract}

Palavras-chave: sociedade da informação; exclusão digital; direitos fundamentais.

\begin{abstract}
This article discusses the contemporary phenomenon of digital exclusion and the possibility of it decreases with government intervention in the form of educational public policies. It also addresses the application of Information and communications technology for the development of educational skills, as a way of alleviating social exclusion. Its methodology is based on the conceptual definition of digital exclusion and analysis of government policies that have been implemented in order to overcome them. It is therefore search concept theoretical law on the basis of deductive analytical method. Concludes by identifying the importance of implementing measures to overcome barriers and reduce the gap between those who enjoy fully the benefits from new technologies and those who are excluded for social, economic, geographic or demographic reasons. This decrease in electron segregation requires the performance of the government, through policies that address the called digital excluison that separates significant portions of society off the largesse offered by the Internet communication platforms.
\end{abstract}

Keywords: information society, digital exclusion; fundamental rights 


\section{SUMÁRIO}

INTRODUÇAO; 1 EXCLUSÃO DIGITAL; 2 INCLUSÃO DIGITAL, EDUCAÇÃO E DESENVOLVIMENTO DE HABILIDADES; 3 REDEFINIÇÃO DO PAPEL DO ESTADO BRASILEIRO NOS SERVIÇOS DE TELECOMUNICAÇÕES E A INCLUSÃO DIGITAL; CONCLUSÃO; REFERÊNCIAS

\section{INTRODUÇÃO}

Este artigo aborda o fenômeno contemporâneo da exclusão digital e a possibilidade de mitigá-lo por intermédio de intervenções governamentais no formato de políticas públicas educacionais e a aplicação das Tecnologias da Informação e da Comunicação para o desenvolvimento de habilidades. Nesse ensejo, não se pode olvidar que a sociedade contemporânea vivencia contínuas transformações que revelam uma silenciosa, mas perceptível, revolução, denominada Sociedade da Informação. Esse movimento foi alavancado pelo desenvolvimento de novas tecnologias que promovem a eliminação de barreiras para a comunicação entre os indivíduos, disseminando e massificando a informação pelas mídias digitais.

Dessa revolução emergiu e encontra-se em formação um novo território, um novo ambiente de convivência e de relações sociais - o ambiente virtual - que aos cidadãos se mostra através da rede mundial de computadores, a internet. 0 intercâmbio e a difusão de informações ocorrem numa intensidade e rapidez sem precedentes, afetando o modo de vida da sociedade contemporânea.

Tal revolução, sob o aspecto econômico e financeiro, é impulsionada e potencializada pelo fenômeno da globalização que permitiu a mundialização da produção industrial e do comércio e, paulatinamente, atenua as fronteiras físicas que separam os países. Nesse cenário, vislumbra-se a necessidade de implementação de medidas para transpor barreiras e reduzir as distâncias entre aqueles que usufruem plenamente das benesses advindas das novas tecnologias e aqueles que, por razões sociais, econômicas, geográficas ou demográficas, têm tolhido o pleno acesso às novas tecnologias. A diminuição da segregação eletrônica exige a atuação do poder público, por intermédio de políticas que enfrentem a denominada exclusão digital, que assume uma face ainda mais perversa que a desigualdade clássica, uma vez que aparta parcelas significativas da sociedade das benesses oferecidas pelas plataformas comunicativas da Internet.

0 artigo subdivide-se na definição conceitual da exclusão digital para, em seguida, tratar da inclusão digital como fator potencialmente propulsor de políticas educacionais e, por REDESG / Revista Direitos Emergentes na Sociedade Global - www.ufsm.br/redesg v. 1, n. 1, jan.jun/2012 
fim, abordar o contexto de redefinição do papel do Estado Brasileiro nos serviços de telecomunicações e a inclusão digital.

\section{A EXCLUSÃO DIGITAL}

Verifica-se na sociedade contemporânea a valorização da informação e do conhecimento, e, em decorrência dessa necessidade, valorizam-se as técnicas e as tecnologias necessárias para obtê-los com a rapidez que o mundo capitalista globalizado exige:

Como a tendência da economia capitalista é se tornar crescentemente baseada em informações e em bens intangíveis, a disputa pelo conhecimento das técnicas e tecnologias de armazenamento, processamento e transmissão das informações assume o centro estratégico das economias nacionais. Saber fazer programas de computador será cada vez mais vital para um país. Tudo indica que os softwares serão elementos de crescente utilidade econômica e de alto valor agregado. ${ }^{1}$

Contudo, com a intensificação do uso econômico das tecnologias da informação das comunicações, principalmente da internet, a serviço da globalização econômica, ou seja, da mundialização dos mercados e da conquista de novos consumidores sob a bandeira do capitalismo imperialista, a sociedade brasileira viu surgir uma nova classe de marginalizados, que decorre ou se soma aos demais grupos excluídos do referido sistema econômico dominante, os denominados digitalmente excluídos. De fato, conforme leciona Silveira:

[...] o mercado capitalista não incluiu todos os indivíduos na sociedade dos alfabetizados. Há poucos indícios que o mercado hipercapitalista, fundamentalmente digital, será capaz de incluir as pessoas na sociedade informacional. Mesmo com a queda dos preços dos produtos informacionais, com o avanço da internet móvel via aparelhos celulares, com a venda de computadores ultrapassando, pela primeira vez, a venda de televisores no Brasil, as desigualdades socioeconômicas são um gigantesco entrave para o exercício do direito humano básico à comunicação na era digital. ${ }^{2}$

Nessa seara de marginalização, inerente ao modo de produção capitalista, o surgimento e o aperfeiçoamento de meios de comunicação, capazes de propagar rapidamente informações incentivando a troca de conhecimentos e estreitando distâncias para relações pessoais,

\footnotetext{
${ }^{1}$ SILVEIRA, Sergio Amadeu da. Software Livre: a luta pela liberdade do conhecimento. São Paulo: Editora Fundação Perseu Abramo, 2004, p. 06.

2 SILVEIRA, Sergio Amadeu da. A Noção de Exclusão Digital diante das Exigências de uma Cibercidadania. In: HETKOWSKI, Tânia Maria (org.). Políticas Públicas \& Inclusão Digital. Salvador: EDUFBA, 2008, p. 55.

REDESG / Revista Direitos Emergentes na Sociedade Global - www.ufsm.br/redesg v. 1, n. 1, jan.jun/2012
} 
profissionais e comerciais, que são de acesso restrito aos mais abastados economicamente, mostra outra face da desigualdade social, posto que no entendimento de Sorj:

A exclusão digital representa uma dimensão da desigualdade social: ela mede a distância relativa do acesso a produtos, serviços e benefícios das novas tecnologias da informação e da comunicação entre diferentes segmentos da população. A exclusão digital trata igualmente de um outro tema associado à questão de desigualdade social, mas que não pode ser confundido com esta: a telemática como instrumento de luta contra a pobreza.

Em situações de crescimento econômico, é possível diminuir a pobreza (a população que se encontra abaixo do que é considerado o mínimo necessário para viver numa sociedade dada) e, ao mesmo tempo, aumentar a desigualdade social. A luta contra a desigualdade e a contra a pobreza apresentam, portanto, superposições, mas não são sinônimas.

Como toda inovação social, o impacto da telemática aumenta potencialmente a desigualdade social, já que dela se apropriam inicialmente os setores mais ricos da população. Assim, a luta contra a exclusão digital não é tanto uma luta para diminuir a desigualdade social, mas um esforço para não permitir que a desigualdade cresça ainda mais com as vantagens que os grupos da população com mais recursos e educação podem obter pelo acesso exclusivo a este instrumento. ${ }^{3}$

Com a mesma visão, Dupas identifica no mundo contemporâneo um verdadeiro “apartheid digital”, acarretado pela dificuldade de acesso à internet, seja por questões econômicas, educacionais, funcionais e tecnológicas que dificultam ainda mais a integração das camadas marginais da sociedade:

A abrangência e a intensidade do uso da internet na maioria das áreas da atividade social, econômica e política leva à marginalidade os que têm acesso apenas limitado a ela. É o apartheid digital. À medida que as tecnologias de acesso se tornam mais complexas, desacelera-se sua adoção pelos grupos de menor nível educacional e de renda. Como a capacidade de processar informações torna-se essencial, aqueles que têm limitações para aproveitar esse acesso ficam muito atrás dos outros. Educação, informação, ciência e tecnologia tornam-se essenciais para gerar valor na economia baseada na internet, mas exigem investimentos contínuos e muito elevados. ${ }^{4}$

Acerca da exclusão digital como fenômeno da Sociedade da Informação, Pierre Lévy, entendendo como naturais seus reflexos, ressalta que devemos considerar que cada novo sistema de comunicação cria seus excluídos:

\footnotetext{
${ }^{3}$ Op. cit., 2003, p. 62.

${ }^{4}$ DUPAS, Gilberto. Atores e Poderes na Nova Ordem Global: assimetrias, instabilidades e imperativos de legitimação. São Paulo: Unesp, 2005, p. 201.

REDESG / Revista Direitos Emergentes na Sociedade Global - www.ufsm.br/redesg v. 1, n. 1, jan.jun/2012
} 
Cada novo sistema de comunicação fabrica excluídos. Não havia iletrados antes da invenção da escrita. A impressão e a televisão introduziram a divisão entre aqueles que publicam ou estão na mídia e os outros. ${ }^{5}$

Contudo, deve-se ter em mente que ao contrário de aceitar como naturais e minimizar o impacto dos processos de exclusão noticiados por Lévy, é importante em um mundo combater o surgimento de cada nova forma de exclusão, posto que as mesmas se somam, avolumam-se, criando uma verdadeira multidão de pessoas invisíveis para a sociedade em vários aspectos relacionados aos direitos coletivos e sociais.

Sob tal enfoque, contudo, há de se reconhecer que somente possibilitar o acesso à rede mundial de computadores por si só não garante que o cidadão irá adquirir habilidades para se comunicar, para exercer lucidamente seus direitos e se articular nas redes digitais; mas, de qualquer forma, é claro que no mundo contemporâneo marcado pelo fenômeno da internet, sem o acesso aos instrumentos intermediários que asseguram a comunicação digital (a máquina de processar, a conexão e a infraestrutura de banda larga), o exercício de direitos fundamentais fica prejudicado, bem como resta restringida a participação democrática do cidadão, até porque, como bem coloca Silveira:

Apenas o acesso não garante a equidade social e cultural, do mesmo modo que somente a democracia não implica em desenvolvimento. Mas lutar pelo democracia é vital para a cidadania, do mesmo modo que combater a exclusão digital é um dos fundamentos de uma cidadania na era informacional. ${ }^{6}$

No contexto atual da sociedade em rede, de acordo com a expressão de Manuel Castells, Klaus Frey ${ }^{7}$ aponta que são os grupos sociais mais poderosos que têm as melhores capacidades de adaptação. Estes grupos se valem das potencialidades abertas pela globalização pelas novas tecnologias da informação e comunicação para consolidar suas identidades grupais e para fortalecer sua capacidade de atuação em um mundo cada vez mais interdependente, cenário que acentua ainda mais o quadro de desigualdade preexistente com um fator catalisador: o avanço tecnológico.

Acerca da desigualdade preexistente, Lévy assim concluiu:

O ciberespaço não muda nada o fato de que há relações de poder e desigualdade econômica entre humanos. Mas, para pegar um exemplo facilmente

\footnotetext{
${ }^{5}$ Op. cit., 1999, p. 237.

${ }^{6}$ Op. cit., 2008, p. 56.

${ }^{7}$ FREY, Klaus. Nueva Sociedad. Gobernanza Eletrónica Urbana e Inclusión Digital: experiencias en ciudades europeas y brasileñas. Revista Nueva Sociedad, Madrid, n. 196, pp. 109-124, março/abril, 2005.

REDESG / Revista Direitos Emergentes na Sociedade Global - www.ufsm.br/redesg v. 1, n. 1, jan.jun/2012
} 
compreensível, o poder e a riqueza não se distribuem nem se exercem da mesma maneira em uma sociedade de castas, com privilégios hereditários, economicamente bloqueada pelos monopólios corporativos e em uma sociedade cujos cidadãos têm os mesmos direitos, cujas leis favorecem a livre empresa e lutam contra os monopólios. ${ }^{8}$

Lévy, conforme acima mencionado, reconhece que a expansão da cibercultura do mundo digital é atualmente mais um fator de exclusão, "tanto entre as classes de uma sociedade como entre as nações de países ricos e pobres", na medida em que para acessar a internet é necessário ter os instrumentos adequados e recursos financeiros para acompanhar o vertiginoso avanço tecnológico, para investir em capacitação e em uma infraestrutura de comunicação que requer computadores potentes, além de redes e sistema complexos de telecomunicações.

Contudo, em que pesem os entraves excludentes acarretados pelos problemas sociais que impedem o acesso de uma parcela considerável da população, Lévy, em uma visão otimista, prevê que será cada vez mais fácil e barato conectar-se, porém alerta que não basta garantir o acesso às novas tecnologias, deve-se garantir que todos possam interagir e ganhar autonomia no ciberespaço:

[...] o problema de 'acesso a todos' não pode ser reduzido a dimensões tecnológicas e financeiras geralmente apresentadas. Não basta estar na frente de uma tela, munido de todas interfaces amigáveis que se possa pensar, para superar uma situação de inferioridade. É preciso antes de mais nada estar em condições de participar ativamente dos processos de inteligência coletiva que representam o principal interesse do ciberespaço.

[...] Em ouras palavras, na perspectiva da cibercultura assim como das abordagens mais clássicas, as políticas voluntaristas de luta contra as desigualdades e a exclusão devem visar o ganho em autonomia das pessoas e grupos envolvidos. ${ }^{9}$

No tocante à exclusão digital no Brasil, nos moldes da pesquisa realizada em 2010 nos domicílios brasileiros e divulgada pelo Comitê Gestor da Internet no Brasil (CGI.br) ${ }^{10}$, no país, como um todo, há presença de computador em apenas 35\% das residências. Tal fato escancara o grande desafio que é universalizar o acesso às tecnologia da informação e comunicação, observando ainda que existem grandes diferenças setoriais, regionais e econômicas que aumentam o problema:

As diferenças setoriais (urbano e rural), regionais e econômicas (renda familiar) no crescimento da posse de computador no país requerem atenção,

\footnotetext{
${ }^{8}$ Op. cit., 1999, pp. 231-232.

${ }^{9}$ Op. cit., 1999, p. 238.

${ }_{10}$ TIC Domicílios e Empresas 2010. Pesquisa sobre o uso das tecnologias de informação e comunicação no Brasil. Disponível em: <http://www.cgi.br/publicacoes/index.htm>. Acesso em: 31 mar.2012.

REDESG / Revista Direitos Emergentes na Sociedade Global - www.ufsm.br/redesg v. 1, n. 1, jan.jun/2012
} 
especialmente por indicarem possível ampliação das desigualdades de inclusão digital. Reduzir essas desproporcionalidades é fundamental para que as distâncias sociais, principalmente em relação à inclusão digital, não se intensifiquem ao longo dos próximos anos. Um exemplo disso é a crescente diferença do acesso às TIC entre a área urbana e a rural. Em 2009, 36\% dos domicílios urbanos possuíam pelo menos um computador, enquanto na área rural, apenas $12 \%$. Em 2010, a penetração do computador não se alterou nos lares rurais, e a diferença entre essas regiões, que era de 24 pontos percentuais, aumentou para 27.

A taxa de crescimento da posse de computadores nas áreas urbanas varia também conforme a região. Enquanto nas regiões Nordeste e Sul o crescimento foi de apenas 1 ponto percentual em relação à medição anterior, nas regiões Norte e Centro-Oeste, esse crescimento chegou a 4 e 7 pontos, respectivamente, e na região Sudeste, a 2 pontos percentuais. ${ }^{11}$

Além da reduzida posse de computadores, o estudo realizado em 2010 também apontou que nos domicílios brasileiros o acesso à internet ainda é pequeno, embora tenha ocorrido o crescimento acima mencionado em comparação com as pesquisas anteriores, passando de $21 \%$ a $27 \%$ :

A presença do acesso à Internet em apenas $27 \%$ dos domicílios brasileiros coloca - Brasil diante de um grande desafio no processo de universalização da banda larga e da democratização do acesso à informação, duas questões centrais para o desenvolvimento do país nas próximas décadas. Segundo dados do relatório da ITU-D, já mencionado no quesito acesso à Internet, em 2008 a posição do Brasil também era desfavorável no cenário internacional, com apenas $21 \%$ dos domicílios conectados à rede. Quando comparado com países da América do Sul, por exemplo, o Chile possuía $24 \%$ e a Argentina, 30\%. Comparando-se com países da Europa e Ásia, onde o acesso à Internet encontra-se praticamente universalizado, a distância era ainda maior: Alemanha (75\%), Dinamarca $(82 \%)$,Suécia (84\%), Japão $(80 \%)$ e Coreia $(94 \%){ }^{12}$

Ademais disso, embora o acesso à internet tenha aumento no Brasil, a pesquisa de 2010 aponta uma queda no nível desse crescimento, ocasionado, principalmente, pelo baixo crescimento de algumas áreas ou regiões específicas do país:

Em 2010, o acesso à Internet nos domicílios urbanos cresceu 15\% em relação ao ano anterior, porém com uma taxa inferior à verificada em 2009, ano em que a taxa de crescimento foi a maior da série histórica: 35\% em relação a 2008. A taxa composta de crescimento anual desse quesito foi de $19 \%$ no período entre 2005 e 2010 (...). Embora apresentem oscilações no período de 2005 a 2010, com exceção de 2005-2006, as taxas de crescimento anual estiveram sempre em patamares muito próximos ou acima da taxa composta do período (19\%), o que não ocorreu em 2010 (15\%). Contudo isso não significa necessariamente uma tendência de estabilidade ou desaceleração na taxa de crescimento do acesso à Internet nos domicílios brasileiros. Quando se comparam as proporções de domicílios nas áreas urbanas com acesso à Internet desde 2005, nota-se que o

\footnotetext{
${ }^{11}$ Op. cit. Acesso em: 31/03/2012.

${ }^{12}$ Op. cit. Acesso em: 31/03/2012.
}

REDESG / Revista Direitos Emergentes na Sociedade Global - www.ufsm.br/redesg v. 1, n. 1, jan.jun/2012 
crescimento é de no máximo 3 pontos percentuais por ano. No entanto, entre 2008 e 2009 verifica-se um crescimento de 7 pontos percentuais. Entre 2009 e 2010, a taxa de crescimento continua positiva - 4 pontos percentuais -, mas menor em relação à do ano anterior.

Cabe ressaltar que, em 2010, a queda do crescimento da proporção de domicílios com acesso à Internet em relação a 2009 também está associada ao baixo crescimento do acesso em algumas áreas e regiões específicas. No Total Brasil, a área rural e as regiões Nordeste e Sul praticamente mantiveram o indicador no mesmo patamar da edição anterior. ${ }^{13}$

A mesma conclusão se extrai da análise dos dados da posse de computadores nos domicílios brasileiros, que também aponta queda no nível de crescimento:

Nos últimos seis anos, a proporção de domicílios com computadores na área urbana mais do que dobrou no país: de $17 \%$, em 2005, para 39\%, em 2010. Nesse período, a taxa composta de crescimento anual foi de 18\%, mas em 2010 o crescimento foi de apenas $8 \%$ em relação a 2009. Quanto à posse da conexão de Internet nos domicílios urbanos, a proporção passou de $13 \%$, em 2005 , para $31 \%$, em 2010. Nesse período, a taxa composta de crescimento anual foi de $19 \%$, e em 2010 a taxa de crescimento foi de 15\% em relação a 2009.

Verifica-se, portanto, que em 2010 as taxas de crescimento da posse e do uso do computador e da conexão à Internet estão abaixo da taxa composta de crescimento anual dos últimos seis anos, o que evidencia a necessidade de se investigar ainda mais, e de diferentes formas, fatores que podem interferir ou favorecer esse crescimento, visando à universalização das TIC nos domicílios brasileiros. As áreas urbanas e rurais, inseridas em contextos socioeconômicos distintos, apresentam crescimento proporcionalmente desigual de acesso e uso das TIC pela população. Nesse sentido, o avanço da pesquisa TIC Domicílios para as áreas rurais, em 2008, trouxe ganhos expressivos para a compreensão das dinâmicas e dificuldades associadas à inclusão digital que são particulares às diferentes áreas do país. ${ }^{14}$

As tecnologias de informação e comunicação constituem importante motor para o desenvolvimento socioeconômico e cultural do país e, para o acesso à internet, em particular, as conexões de banda larga são essenciais para a adoção efetiva dessas tecnologias pela população. A utilização das TIC, seguida de sua apropriação, tem implicações sociais e possíveis impactos no crescimento econômico do Brasil.

A expansão do acesso de banda larga está presente na agenda política de muitos países, que, neste momento, discutem metas para sua universalização, como foi o caso da iniciativa do governo brasileiro ao lançar o Plano Nacional de Banda Larga (PNBL), cujo objetivo é massificar a oferta de acessos de banda larga à internet nos domicílios brasileiros até o ano de 2014.

\footnotetext{
${ }_{13}$ Op. cit. Acesso em: $31 / 03 / 2012$.
}

${ }^{14}$ Op. cit. Acesso em: 31/03/2012.

REDESG / Revista Direitos Emergentes na Sociedade Global - www.ufsm.br/redesg v. 1, n. 1, jan.jun/2012 
Dada a importância atribuída à universalização desse tipo de conexão, organizações como a OCDE, o Banco Mundial e o Instituto de Pesquisa Econômica Aplicada (Ipea) ${ }^{15}$ estudam os possíveis impactos da expansão do acesso à internet de banda larga sobre desempenho econômico, crescimento do PIB e competitividade das nações.

Dessa forma, é importante destacar as seguintes conclusões da pesquisa acerca do acesso à internet nos domicílios brasileiros ${ }^{16}$ :

- Os domicílios da classe C apresentam crescimento proporcionalmente maior quando comparado ao das demais classes sociais.

- A região Centro-Oeste se destaca, com crescimento de 8 pontos percentuais, registrando acesso à internet em 33\% dos lares no Total Brasil.

- $\quad$ Ainda existem cerca de 4,6 milhões de domicílios que possuem pelo menos um computador, mas sem acesso à rede.

- Nesta edição da pesquisa, nota-se mais uma vez a queda do acesso discado, presente em apenas $13 \%$ dos domicílios da zona urbana, e um aumento das conexões de banda larga fixa, presente em 68\% dos domicílios urbanos com acesso à internet.

- Os indicadores retratam um aumento expressivo de conexões de banda larga móvel.

- Nota-se um crescimento expressivo das conexões de tipo banda larga fixa, especialmente na zona rural do país: entre 2009 e 2010, cresceu 9 pontos percentuais. Por outro lado, conexões de banda larga móvel (como o 3G) cresceram tanto nas áreas urbanas como nas rurais. Nas áreas urbanas, o crescimento foi de $67 \%$ em relação a 2009, e nas áreas rurais, 63\%.

- $\quad$ No total geral, houve uma queda da conexão discada em todas as regiões, sendo que no Sul e no Centro-Oeste registra-se o menor índice: 9\% de domicílios que ainda utilizam esse tipo de conexão. No entanto, na região Norte, $21 \%$ das conexões domiciliares à internet ainda são realizadas por acesso discado.

- A banda larga fixa e banda larga móvel cresceram de maneira desigual nas diferentes regiões. Em relação a 2009, no Total Brasil, as conexões de banda larga fixa cresceram em maior medida nas regiões Norte e Sul, respectivamente $8 \%$ e 10\%; nas demais

15 O IPEA é uma fundação pública federal vinculada à Secretaria de Assuntos Estratégicos da Presidência da República. Suas atividades de pesquisa fornecem suporte técnico e institucional às ações governamentais para a formulação e reformulação de políticas públicas e programas de desenvolvimento brasileiros.

${ }^{16}$ Op. cit. Acesso em: 31/03/2012.

REDESG / Revista Direitos Emergentes na Sociedade Global - www.ufsm.br/redesg v. 1, n. 1, jan.jun/2012 
regiões, a proporção de domicílios com esse tipo de conexão praticamente se manteve estável no Nordeste, no Sudeste e no Centro-Oeste, o crescimento foi de 3\%, 2\% e 2\%, respectivamente. A maior penetração da banda larga fixa está na região Sul (78\%), seguida por Sudeste (67\%) e Centro-Oeste (66\%), no Total Brasil.

É importante ressaltar que um dado que chama a atenção para a desigualdade no acesso à internet é o fato de a região nordeste, apesar de ter a segunda maior população do Brasil, ser a que possui índices socioeconômicos dos mais desfavoráveis e, além disso, ser a que apresenta as mais baixas taxas de acesso às tecnologias da informação e da comunicação, tanto em termos de posse como de uso dessas ferramentas. Além disso, referida região apresenta as menores proporções relativas de crescimento, entre 2009 e 2010, em diferentes indicadores de posse e uso das TIC - o que leva a concluir que a desigualdade regional está, nesse aspecto, aumentando.

Diante da exposição dos dados da pesquisa TIC Domicílio 2010 acima salientados, ainda é importante frisar que com relação ao dado "computador e internet no domicílio", constatou-se que a taxa de crescimento da presença de computador e do acesso à internet nos domicílios brasileiros foi menor do que nos anos anteriores da pesquisa. Tal fato impõe a necessidade de uma revisão nas políticas e estratégias de inclusão digital atualmente implantadas, para que se efetive a redução das barreiras para a posse e uso das tecnologias da informação e comunicação nos domicílios brasileiros.

Também é importante mencionar que o referido estudo revelou que a posse de notebooks apresentou um relevante crescimento em todo o país, passando de 5\%, em 2009, para $8 \%$, em 2010, aumentando também o número de domicílios que possuem apenas esses computadores portáteis, fato que leva a crer que esse tipo de máquina é o primeiro computador a ser adquirido em muitos lares, notadamente nos domicílios da classe $C$.

Acrescente-se ainda que ao mesmo tempo em que a pesquisa demonstra um crescimento do uso da rede mundial de computadores nos domicílios, também revela uma queda no uso de lanhouses como local de acesso à internet, embora esse ambiente ainda seja o segundo local mais utilizado para acesso à rede pelos brasileiros.

O mais importante para o contexto da inclusão digital e social é que a pesquisa comprova que a proporção de brasileiros usuários de internet de fato cresceu e configura, lentamente, uma mudança no perfil do internauta, posto que há maior presença na rede de brasileiros com menor grau de escolaridade e de classes sociais mais baixas. Tal situação, 
segundo aponta o estudo, ocorre possivelmente em função da mobilidade social e do crescimento da classe $C$ nos últimos anos.

\section{INCLUSÃO DIGITAL, EDUCAÇÃO E DESENVOLVIMENTO DE HABILIDADES}

Contudo, deve-se ter em mente que inclusão digital não significa apenas ter acesso a um computador e à internet. É preciso saber utilizar esses recursos para atividades variadas, classificadas em três diferentes patamares, segundo sua relação com o exercício da cidadania. Em um primeiro nível, a internet, hoje especialmente através das redes sociais, permite a comunicação entre as pessoas, o que já potencializa formas de articulação em torno de demandas sociais variadas. Em um segundo nível, a internet viabiliza a obtenção de informações e a utilização de serviços de interesse público. Em um terceiro patamar, no entanto, certamente ainda mais importante para a cidadania e a nação, a inclusão digital deve permitir a geração e a disponibilização de conteúdo, através das mais diferentes formas - geração de conteúdos multimídia, digitalização de conteúdos variados, criação de páginas e de blogs etc. Conforme aponta Flávio Rech Wagner:

Para uma efetiva utilização dos recursos computacionais que permitem a inclusão digital, os usuários precisam adquirir habilidades variadas, que podem ser associadas aos três patamares antes mencionados. Essas habilidades incluem, por exemplo, a manipulação dos recursos básicos de um computador dotado de um sistema operacional, tais como a utilização de arquivos de texto e de outras mídias, de diretórios e de periféricos, assim como a instalação de programas. Incluem ainda a elaboração de documentos de diversos tipos, o uso de máquinas de busca e de programas de correio eletrônico, o preenchimento de formulários eletrônicos, entre outras. Além disto, o usuário precisa ter noções básicas de segurança, compreendendo os diversos tipos de riscos inerentes à Internet, além de ser capaz de tomar as medidas básicas para evitá-los. ${ }^{17}$

Assim, a educação, que sem dúvida é a grande ferramenta de inclusão social dos países em desenvolvimento, não será plenamente atingida sem a capacitação tecnológica dos usuários dos meios digitais e sem a oferta de acesso às novas tecnologias, seja pela universalização dos serviços de telecomunicações ou pelo incentivo à implantação de terminais de acesso gratuito ou de baixo custo, como, por exemplo, telecentros instalados em locais estratégicos e de fácil acesso para os usuários, como terminais de ônibus, estações de metrô e de trem, escolas e

\footnotetext{
17 WAGNER, Flávio Rech. - Habilidade e Inclusão Digital - O Papel das Escolas. Disponível em: <http://www.cgi.br/publicacoes/artigos/artigo64.htm>. Acesso em: 31 mar.2012.
}

REDESG / Revista Direitos Emergentes na Sociedade Global - www.ufsm.br/redesg v. 1, n. 1, jan.jun/2012 
bibliotecas públicas etc. Contudo, não basta o governo oferecer apenas os instrumentos tecnológicos - computadores, internet, etc. É necessário introduzir conteúdos, qualidade, treinamento e monitoramento nos programas de inclusão digital.

Tal entendimento é corroborado pelos resultados da pesquisa TIC Domicílios e Empresas $2010^{18}$, na qual restou apurado que entre aqueles que ainda não possuem computador em seus lares no Brasil como um todo, as principais barreiras para sua aquisição, além do custo elevado dessa máquina (74\% dos domicílios), seriam a falta de interesse e a falta de habilidade que também são motivos bastante recorrentes, citados respectivamente por $38 \%$ e $26 \%$ dos domicílios sem computador. Destarte, a pesquisa indica que além de questões estruturais que remetem ao custo do equipamento, a ampliação da posse de computador nos domicílios depende não somente do acesso às TIC propriamente dito, mas também do desenvolvimento de habilidades a partir de uma maior alfabetização digital da população.

Segundo Takahashi" ${ }^{19}$, alfabetização digital pode ser definida como a "aquisição de habilidades básicas para o uso de computadores e da Internet [...] em favor dos interesses e necessidades individuais e comunitários, com responsabilidade e senso de cidadania”.

Nesse esteio, estudos desenvolvidos pela $\mathrm{UNESCO}^{20}$ revelam que a proliferação dos meios de comunicação trouxe mudanças decisivas no comportamento humano e nos processos de comunicação. Nesse sentido, a educação para o uso e apropriação das novas mídias torna-se essencial para capacitar os cidadãos, proporcionando-lhes as competências, as atitudes e as habilidades necessárias para garantir o direito universal à informação e à liberdade de expressão por meio das TIC.

Conforme se aduz dos dados da pesquisa TIC Domicílio $2010^{21}$, as habilidades relacionadas ao uso do computador, tais como copiar ou mover arquivos ou pastas, usar planilhas e conectar ou instalar periféricos, são de grande relevância para o desenvolvimento da Sociedade da Informação. Segundo a referida pesquisa, que acompanha anualmente indicadores que medem as habilidades relacionadas ao uso do computador, copiar ou mover arquivos e usar programas para edição de texto são as habilidades mais desenvolvidas. Outras atividades ainda

\footnotetext{
${ }^{18}$ Op. cit. Acesso em: 31/03/2012.

19 TAKAHASHI, T. (org.). Socinfo: Sociedade da Informação no Brasil: Livro Verde. Brasília: Ministério da Ciência e Tecnologia, 2000, p. 31.

20 Relatório da Unesco, Media Education: A Kit for Teachers, Students, Parents and Professionals. Disponível em: http://www.unesco.org/new/es/unesco/resources/publications/unesdoc-database/. Acesso em 05/05/2012.

${ }^{21}$ Op. cit.. Acesso em: $31 \mathrm{mar} .2012$.

REDESG / Revista Direitos Emergentes na Sociedade Global - www.ufsm.br/redesg v. 1, n. 1, jan.jun/2012
} 
são pouco difundidas, como comprimir arquivos e apenas $18 \%$ dos pesquisados, notadamente os mais jovens, apontaram ter habilidade para escrever um programa de computador.

Ademais disso, a pesquisa acompanha desde 2007 o aumento do índice percentual de usuários que obtêm as habilidades por conta própria, verificando que com o avanço das novas tecnologias são disponibilizados aplicativos auto-explicativos e mais intuitivos, que facilitam o aprendizado e favorecem a autonomia do usuário no desenvolvimento de habilidades. Contudo é importante citar que, conforme constatou o estudo, as principais barreiras para aqueles que consideram não ter aptidão suficiente para competir no mercado de trabalho são o alto custo dos cursos formais para o desenvolvimento das habilidades, bem como a falta de tempo, que também são motivos que inibem o aprendizado em instituições de ensino:

Entre os usuários de computador na área urbana, 69\% afirmam que adquiriram suas habilidades por conta própria, e $42 \%$ com parentes, amigos ou colegas de trabalho. 0 aprendizado de maneira formal é citado por menores parcelas da população: nas áreas urbanas, 30\% afirmam ter adquirido alguma habilidade via cursos de treinamento pago, $7 \%$ em cursos gratuitos, $5 \%$ em cursos pagos pelo empregador e $17 \%$ em uma instituição formal de ensino. Esses resultados evidenciam a importância do auto aprendizado, especialmente quando se comparam essas proporções aos resultados das pesquisas anteriores. ${ }^{22}$

Depreende-se, portanto, nos dizeres de Silveira ${ }^{23}$, que o desenvolvimento das Tecnologias da Informação e da Comunicação (TIC) e sua desigual apropriação pelos diferentes estratos sociais vieram acrescentar ao rol das desigualdades sociais já existentes uma desigualdade de novo tipo ou forma, cuja face mais aparente se mostra através da privação do acesso da população mais pobre ao computador, à internet e aos conhecimentos básicos para os utilizar.

Assim, a inclusão digital tornou-se uma questão de alta relevância social, econômica e política, e sendo analisada de forma mais ampla do que o simples acesso ao computador, a Inclusão Digital é, na realidade, nas palavras de Bruno Pires Malaquias:

[...] um conceito que engloba as novas tecnologias da informação e comunicação, a educação, o protagonismo, possibilitando a construção de uma cidadania criativa e empreendedora. A Inclusão Digital é um meio para promover a melhoria da qualidade de vida, garantir maior liberdade social, gerar conhecimento e troca de informações. Temos, então o surgimento do excluído digital, o marginalizado do século XXI. ${ }^{24}$

\footnotetext{
${ }^{22}$ Op. cit.. Acesso em: 31/03/2012.

23 SILVEIRA, Sergio Amadeu da. Inclusão Digital, Software Livre e Globalização contra Hegemônica. In: — (Org.). Software livre e inclusão digital. São Paulo: Conrad, 2003, p. 18.

${ }^{24}$ Op. cit. Acesso em 25 fev. 2012.

REDESG / Revista Direitos Emergentes na Sociedade Global - www.ufsm.br/redesg v. 1, n. 1, jan.jun/2012
} 
De fato, constata-se no contexto atual a distribuição irregular do acesso entre diferentes sociedades e no interior das mesmas, conforme expressão de estatísticas públicas já mencionadas neste capítulo e, nesse cenário, acentua-se o papel incentivador e provedor do Estado, que deverá, para atenuar os índices de desigualdade, promover o princípio da universalização dos serviços de telecomunicações, notadamente o acesso à internet, como forma de efetivar o direito fundamental à informação, como bem realça Botelho:

Neste sentido, o princípio da universalização dos serviços de telecomunicações não apenas nasce do fundamento elementar do Estado brasileiro - de redução das desigualdades (art. 3o, III, da CF) - mas, essencialmente, sintetiza implemento de igualdade, que haverá de ser materialmente considerada, ou considerada em razão de particularidades regionais e grupais (inclusive étnicas, religiosas, culturais, regionais). Assim, um mesmo serviço telecomunicativo haverá de ser levado, por comando público a cargo do Estado, a todo e qualquer usuário, qualquer que seja sua condição sócio-econômico-geográfico-cultural-racial.

O implemento da inclusão digital textualizará consagração da isonomia cuidada no "caput" do art. 5o, garantia a se prestar ao conjunto dos cidadãos e a cada um em particular. "A contrario sensu", exclusão digital - por exemplo, através da ausência de acesso público-telefônico, de acesso a internet, ou a cabos óticos de alta velocidade, e a outros benefícios da infraestrutura de telecomunicações, alocados a apenas uma minoria da sociedade brasileira - contrariará, sempre e a um só tempo, a igualdade que garante o direito individual (do art. 5o, "caput") e o dever imposto ao Estado, de adimplemento do inciso III, do art. 3o, da CF. ${ }^{25}$

Depreende-se que as inovações tecnológicas no âmbito da informática e das telecomunicações somente serão válidas e benéficas para o cidadão se os governos, em cooperação com a iniciativa privada e terceiro setor, fizerem grandes esforços para reduzir os custos dos equipamentos necessários para o manejo do meio ambiente digital, colocar à disposição da população pontos de acesso gratuitos à internet e, principalmente, promover o treinamento do cidadão comum no uso eficiente e consciente das novas tecnologias da informação e dos seus respectivos conteúdos, pois conforme ressalta Sorj:

A exclusão digital depende de cinco fatores que determinam a maior ou menor universalização dos sistemas telemáticos:

1) a existência de infraestruturas físicas de transmissão;

2) a disponibilidade de equipamento/conexão de acesso (computador, modem, linha de acesso);

3) treinamento no uso dos instrumentos do computador e da Internet;

25 BOTELHO, Fernando Neto. A Inclusão Digital e os Direitos Fundamentais. Disponível em $<$ http://www.wirelessbrasil.org/wirelessbr/colaboradores/fernando_botelho/inclusao_e_direitos_04.html $>$. Acesso em 04/03/2012.

REDESG / Revista Direitos Emergentes na Sociedade Global - www.ufsm.br/redesg v. 1, n. 1, jan.jun/2012 
4) capacitação intelectual e inserção social do usuário, produto da profissão, do nível educacional e intelectual e de sua rede social, que determina o aproveitamento efetivo da informação e das necessidades de comunicação pela Internet;

5) a produção e uso de conteúdos específicos adequados às necessidades dos diversos segmentos da população. ${ }^{26}$

Aludido autor, fazendo uma reflexão sobre as dimensões dos fatores que determinam a universalização dos sistemas telemáticos, bem como da importância de cada um deles, conclui que o Poder Público ainda se concentra principalmente na oferta de infraestrutura e de equipamento de uso individual, o que ainda se mostra insuficiente para propiciar a inclusão completa do cidadão ao mundo digital:

Enquanto os primeiros dois critérios se referem a dimensões passivas do acesso à Internet, as três últimas definem o potencial de apropriação ativa. A distinção entre os diferentes níveis de acesso e uso é fundamental para desenvolver metodologias de avaliação, acompanhamento e atuação na luta contra a exclusão digital. Cada nível, a partir do primeiro, é condição de existência do nível superior, enquanto os níveis superiores determinam a utilidade do nível anterior. Os programas públicos de universalização dos serviços de comunicação focalizam em geral o primeiro e segundo níveis, os das infraestruturas físicas e equipamentos individuais, que são somente parte das precondições para transformar a Internet num serviço público. ${ }^{27}$

Nesse contexto, e reconhecendo a importância da inclusão digital para o desenvolvimento do país, o Poder Executivo Federal editou o Decreto $\mathrm{n}^{\circ} \mathbf{4 . 7 3 3}$, de 10 de junho de 2003, que dispõe sobre políticas públicas de telecomunicações, o qual atribuiu ao Ministério das Comunicações a função de formulação de políticas, diretrizes e metas para esse mister, bem como de coordenação da implementação dos projetos e ações respectivos, no âmbito do programa de inclusão digital, e à Agência Nacional de Telecomunicações - ANATEL determinou que the cabe desenvolver instrumentos, projetos e ações que possibilitem a oferta de planos de serviços de telecomunicações, observando as diretrizes e metas estabelecidas pelo Ministério das Comunicações e o regime de tratamento isonômico como instrumento para redução das desigualdades sociais

${ }^{26}$ Op. cit., 2003, p. 63.
${ }^{27}$ Op. cit., 2003, p. 63.

REDESG / Revista Direitos Emergentes na Sociedade Global - www.ufsm.br/redesg v. 1, n. 1, jan.jun/2012 


\section{REDEFINIÇÃO DO PAPEL DO ESTADO BRASILEIRO NOS SERVIÇOS DE TELECOMUNICAÇÕES E A INCLUSÃO DIGITAL.}

Com a grande demanda de tecnologias da informação - TI, o setor de telecomunicações tornou-se extremamente dinâmico, tanto na oferta de novos serviços quanto na sua qualidade. Porém, até o final dos anos 70, telecomunicações era sinônimo de monopólio da telefonia fixa. A dinâmica do setor envolvia apenas o operador estatal e os fornecedores de equipamentos.

Além das dificuldades de gestão, a opção do governo de manter tarifas abaixo do custo operacional para conter a inflação crônica agravou a escassez de investimentos públicos na década de 80. Em consequência, verificou-se uma grande defasagem tecnológica e uma imensa demanda reprimida por telefonia fixa, que inicialmente prejudicou a expansão do uso e acesso da rede mundial de computadores no Brasil

A TELEBRÁs, que nos inícios dos anos 80 era o maior e um dos melhores sistemas de telecomunicações dos países em desenvolvimento, entrou em declínio com a falta de investimentos, o que culminou no esgotamento do modelo monopolista estatal.

Diante desse cenário, acompanhando a tendência mundial, houve uma redefinição do papel do Estado, com especial ênfase na abertura comercial, privatização de empresas e na desregulamentação de algumas atividades econômicas, visando a configurar um novo modelo para a economia brasileira.

Partiu-se de um modelo nacional-desenvolvimentista (protecionista e intervencionista), marcante no regime militar, para um modelo mais aberto economicamente, fundamentado na ideia de que o setor privado pode ocupar o lugar de antigas empresas estatais na oferta de bens e serviços, como as telecomunicações. A partir desse novo paradigma, tornaram-se evidentes as grandes proporções das deficiências na prestação dos serviços de telecomunicações e a necessidade de novos serviços e investimentos para atender à demanda reprimida. Acrescente-se ainda ao cenário de defasagem o surgimento de novos serviços e tecnologias como internet, celular e outros serviços wireless que implicavam grandes investimentos em tecnologia.

Segundo Castells $^{28}$, com o advento das transformações da década de 90, aliado à demanda crescente por serviços de telecomunicações e aos anseios da opinião pública, surgia

${ }^{28}$ Op. cit., 2007, pp. 119-120

REDESG / Revista Direitos Emergentes na Sociedade Global - www.ufsm.br/redesg v. 1, n. 1, jan.jun/2012 
também a Sociedade da Informação que consiste em um novo paradigma que provocou e continua provocando a necessidade de mudanças, em diversas áreas da sociedade.

No campo econômico, nesse período, já se sentia a influência da globalização, que, nos dizeres de Castells $^{29}$, é um dos grandes problemas colocados à formulação de políticas públicas na atualidade "que ganha uma dimensão especialmente significativa quando se trata de telecomunicações, pois nesse setor a capacidade e a eficácia da ação governamental são bastante reduzidas pela globalização". ${ }^{30}$

Por outro lado, não obstante a onda da mundialização, é crescente a necessidade de novas políticas capazes de promover as mudanças necessárias e proteger os segmentos sociais locais mais vulneráveis. Além disso, a atuação estatal deve ser coerente com o caráter globalizado das telecomunicações e ser compatível com os esforços de regulamentação desenvolvidos em âmbito mundial nos diversos fóruns específicos. ${ }^{31}$

A Lei Geral de Telecomunicações, Lei 9.472, de 16 de julho de 1997, foi um marco para o setor de telecomunicações ao impor que o Estado deixasse de exercer o papel de provedor dos serviços de telecomunicações, passando a somente regular o setor, promover a competição entre a empresas e zelar pelo bem-estar dos usuários, cabendo basicamente à esfera privada a exploração dos serviços. Assim, referido marco legal regulou o setor com o objetivo de zelar pelos interesses dos consumidores, pela padronização tecnológica, pelos investimentos privados e pela segurança nas operações, através de órgão regulador próprio (ANATEL).

De acordo com o artigo $3^{\circ}$ do Decreto $n^{\circ} 4.733 / 2003$, é finalidade das políticas públicas atender o cidadão, observando, entre outros, os seguintes objetivos gerais:

\footnotetext{
I - a inclusão social;

II - a universalização, nos termos da Lei ${ }^{\circ}$ 9.472, de 1997;

III - contribuir efetivamente para a otimização e modernização dos programas de Governo e da prestação dos serviços públicos;

IV - integrar as ações do setor de telecomunicações a outros setores indispensáveis à promoção do desenvolvimento econômico e social do país;

$\mathrm{V}$ - estimular o desenvolvimento industrial brasileiro no setor;

$\mathrm{VI}$ - fomentar a pesquisa e o desenvolvimento tecnológico do setor;

VII - garantir adequado atendimento na prestação dos serviços de telecomunicações;

VIII - estimular a geração de empregos e a capacitação da mão-de-obra; e
}

\footnotetext{
${ }^{29}$ Op. cit, 2007, pp. 119-120.

30 NASCIMENTO, Jamerson Rogério do. Setor de Telecomunicações: História e Políticas Públicas no Brasil. Disponível em : <http://www.ibmecrj.br/sub/RJ/files/dissert_mestrado/ADM_ jamersonnascimento_nov.pdf>. Acesso em: 10 mar.2012.

31 Ibidem.

REDESG / Revista Direitos Emergentes na Sociedade Global - www.ufsm.br/redesg v. 1, n. 1, jan.jun/2012
} 
IX - estimular a competição ampla, livre e justa entre as empresas exploradoras de serviços de telecomunicações, com vistas a promover a diversidade dos serviços com qualidade e a preços acessíveis à população.

Ademais disso, a aludida norma regulamentadora estabelece, em seu artigo $4^{\circ}$, que são objetivos das Políticas Públicas de serviços de telecomunicações:

I - assegurar o acesso individualizado de todos os cidadãos a pelo menos um serviço de telecomunicação e a modicidade das tarifas;

II - garantir o acesso a todos os cidadãos à Rede Mundial de Computadores (Internet);

III - 0 atendimento às necessidades das populações rurais;

IV - o estímulo ao desenvolvimento dos serviços de forma a aperfeiçoar e a ampliar o acesso, de toda a população, às telecomunicações, sob condições de tarifas e de preços justos e razoáveis;

V - a promoção do desenvolvimento e a implantação de formas de fixação, reajuste e revisão de tarifas dos serviços, por intermédio de modelos que assegurem relação justa e coerente entre o custo do serviço e o valor a ser cobrado por sua prestação, assegurado o equilíbrio econômico-financeiro do contrato;

$\mathrm{VI}$ - a garantia do atendimento adequado às necessidades dos cidadãos, relativas aos serviços de telecomunicações com garantia de qualidade;

VII - a organização do serviço de telecomunicações visando a inclusão social.

Parágrafo único. Para assegurar o disposto nos incisos II e VII:

I - o Ministério das Comunicações fica incumbido de formular e propor políticas, diretrizes, objetivos e metas, bem como exercer a coordenação da implementação dos projetos e ações respectivos, no âmbito do programa de inclusão digital;

II - a Agência Nacional de Telecomunicações - ANATEL deverá desenvolver instrumentos, projetos e ações que possibilitem a oferta de planos de serviços de telecomunicações, observando as diretrizes e metas estabelecidas pelo Ministério das Comunicações e o regime de tratamento isonômico como instrumento para redução das desigualdades sociais.

Resta evidente que a inclusão digital também é fator que integra e promove a inclusão social e outros programas sociais do país. Conforme exposto, o Brasil já possui fundamentos constitucionais e infraconstitucionais suficientes para efetivar o direito à inclusão digital como uma extensão do direito fundamental à informação, à liberdade de expressão, à cultura e à educação.

Para Manuel Castells ${ }^{32}$,

[...] todo mundo deveria ter direito a utilizar a Internet e ninguém deveria ser penalizado por questões de geografia ou de dinheiro. Além disso, há outros elementos que fazem com que a divisão digital subsista. Um deles é a velocidade na Internet, e outro é a forma como aqueles que estão no ciberespaço dão forma à Web segundo sua própria imagem. Quanto mais a democratização da Internet demorar, mais a Web se desenvolverá em torno de valores que não são aqueles do conjunto da sociedade. A difusão da Internet sobre o conjunto do planeta

32 Op. cit. Acesso em: 29/03/2012.

REDESG / Revista Direitos Emergentes na Sociedade Global - www.ufsm.br/redesg v. 1, n. 1, jan.jun/2012 
exigirá forte ação dos Estados, com ações públicas nacionais e internacionais. As diferenças culturais, financeiras e de infraestrutura são hoje tais que podemos ter um terço do planeta estruturado ao redor da Internet e dois terços excluídos, com tudo o que isso significa em termos de acesso à informação ou aos recursos empresariais. 0 desenvolvimento da Web, que era exponencial, encontra nessa realidade o seu limite.

Consta-se, portanto, que as garantias fundamentais da Constituição Federal, influenciadas pelo texto universal de direitos do homem de 1948, atreladas ao direito à informação, à liberdade de expressão, à educação, à cultura, e mesmo as prerrogativas que, nas palavras de Marcelo Bechara:

[...] aparentemente não tenham correlação com o processo de inserção na sociedade da informação, só podem ser plenamente alcançadas dentro de um contexto de mundialização e convergência digital, a partir da compreensão de que os avanços tecnológicos devem ser compartilhados entre todos, sob pena dos direitos mais personalíssimos do ser humano restarem cada vez mais distantes. ${ }^{33}$

Depreende-se, assim, que as inovações tecnológicas no âmbito da informática e das telecomunicações somente serão benéficas para o cidadão se os governos, em cooperação com a iniciativa privada e terceiro setor, fizerem grandes esforços para reduzir os custos dos equipamentos necessários para o manejo do meio ambiente digital, colocar à disposição da população pontos de acesso gratuitos à internet e, principalmente, promover o treinamento do cidadão comum no uso eficiente e consciente das novas tecnologias.

\section{CONCLUSÃO}

Os impactos globais nas sociedades contemporâneas, advindos das tecnologias da informação e da comunicação, da disseminação da internet e possibilidade de disseminação do conhecimento, fizeram surgir uma nova geração cada vez mais conectada, que se comunica, adquire e produz serviços e usufrui dos benefícios da ampla gama de informações disponível na rede mundial de computadores, configurando uma nova era, denominada Sociedade da Informação.

Nesse sentido, constata-se que a sociedade, hodiernamente, vivencia transformações que revelam uma perceptível mudança de padrões comportamentais. Essas mudanças decorrem do desenvolvimento contínuo de novas tecnologias que promovem a eliminação de barreiras para

${ }_{33}$ Op. cit.. Acesso em 26/03/2012.

REDESG / Revista Direitos Emergentes na Sociedade Global - www.ufsm.br/redesg v. 1, n. 1, jan.jun/2012 
a comunicação entre os indivíduos, disseminando e massificando a informação pelas mídias digitais, como computadores, telefones celulares e, principalmente, pela internet.

Paradoxalmente, a rede mundial tornou-se um desafio para os poderes públicos, empresas e instituições em escala planetária, pois não há como escapar desse processo de transformação da sociedade e seus reflexos. Além das benesses advindas das novas tecnologias, a disseminação da internet também segrega, alija e exclui pessoas em decorrência de fatores econômicos, sociais, políticos e geográficos. Cria sua outra face da moeda, a perversa exclusão digital. Nesse cenário, o Estado assume um papel muito importante, voltado para a democratização do acesso à rede e a prestação eficiente de seus serviços aos cidadãos, usando as tecnologias de informação e comunicação para promover e ainda efetivar direitos fundamentais. 0 Estado pode promover ações que visem a equilibrar essa balança que pende preferencialmente para o mercado em detrimento da igualdade de acesso às novas tecnologias.

Constata-se que, diante da difusão e da intensificação do uso das tecnologias, bem como pelo impacto da globalização econômica marcada pela política corporativa de grandes conglomerados econômicos, os efeitos no Brasil com o surgimento de uma nova classe de marginalizados socialmente, denominados “digitalmente excluídos”. Essa exclusão assume uma face perversa pois, além de cercear o acesso à internet como ferramenta de lazer e interação social, restringe a possibilidade de participação política, cerceia o exercício pleno da democracia, dificulta o acesso aos meios de colocação e recolocação no mercado de trabalho e alija o efetivo exercício de direitos fundamentais necessários à manutenção da dignidade humana.

Diante desse quadro, revela-se incontestável que esse novo ambiente socioeconômico tem causado impacto não só na sociedade civil, mas também exige respostas da estrutura e gestão dos governos que possuem a indelével missão de possibilitar o acesso universal a essa nova dimensão de cidadania, na qual extensões de direitos fundamentais devem ser garantidas e exercidas.

Acrescente-se ainda que as novas tecnologias da informação e da comunicação ampliam as possibilidades de participação dos cidadãos na tomada de decisões políticas, legitimando de forma mais transparente e eficiente a atuação estatal na busca do interesse público e proteção dos direitos fundamentais.

Nesse diapasão, constata-se na sociedade contemporânea que essa constante modernização das tecnologias da informação e da comunicação geram novos modelos e 
ISSN 2316-3054

parâmetros para direcionar as relações entre os indivíduos e, ainda, afetam as relações entre o Estado e o cidadão. No âmbito do acesso e da efetivação dos direitos fundamentais, a inclusão digital, no contexto brasileiro, deve ser promovida não apenas para dar mais eficiência às ações do Estado, mas, sobretudo, para reafirmar e difundir os instrumentos democráticos, efetivar direitos fundamentais e promover a inclusão sociodigital.

\section{REFERÊNCIAS}

BARRETO JUNIOR, Irineu Francisco. Atualidade do conceito sociedade da informação para a pesquisa jurídica. In: PAESANI, Liliana Minardi (coord.). O Direito na Sociedade da Informação. São Paulo: Atlas, 2007.

. Abordagens Recentes da Pesquisa Jurídica na Sociedade da Informação. In: PAESANI, Liliana Minardi (coord.). O Direito na Sociedade da Informação II. São Paulo: Atlas, 2009.

BOBBIO, Norberto. A Era dos Direitos. Rio de Janeiro: Campus, 2004.

BRASIL. Ministério da Ciência e Tecnologia. Sociedade da Informação no Brasil - Livro Verde. Brasília: setembro, 2000.

CASTELLS, Manuel. A Era da Informação: economia, sociedade e cultura. Volume I, a sociedade em rede. 5.ed. São Paulo: Paz e Terra, 2007.

COMPARATO, Fábio Konder. A Afirmação Histórica dos Direitos Humanos. 7ed. São Paulo: Saraiva, 2010.

DUPAS, Gilberto. Ética e Poder na Sociedade da Informação. 2.ed. São Paulo: UNESP, 2000. . Atores e Poderes na Nova Ordem Global: assimetrias, instabilidades e imperativos de legitimação. São Paulo: Editora Unesp, 2005.

FREY, Klaus. Nueva Sociedad. Gobernanza Eletrónica Urbana e Inclusión Digital: experiencias en ciudades europeas y brasileñas. Revista Nueva Sociedad, Madrid, n. 196, pp. 109-124, março/abril, 2005.

HETKOWSKI, Tânia Maria (org.). Políticas Públicas \& Inclusão Digital. Salvador: EDUFBA, 2008.

PAESANI, Liliana Minardi (org.). Direito na Sociedade da Informação. São Paulo: Atlas, 2007.

PIOVESAN, Flávia. Direitos Humanos e o Direito Constitucional Internacional. 13.ed. São Paulo: Saraiva, 2012.

QUEIROZ, Cristina M. M. Direitos Fundamentais. Coimbra: Coimbra Editora, 2002.

REDESG / Revista Direitos Emergentes na Sociedade Global - www.ufsm.br/redesg v. 1, n. 1, jan.jun/2012 
ISSN 2316-3054

SARLET, Ingo Wolfgang. A Eficácia dos Direitos Fundamentais. 10.ed. Porto Alegre: Livraria do Advogado, 2011.

SILVEIRA, Sergio Amadeu da. Software Livre: a luta pela liberdade do conhecimento. São Paulo: Editora Fundação Perseu Abramo, 2004.

. A Noção de Exclusão Digital diante das Exigências de uma Cibercidadania. In:

HETKOWSKI, Tânia Maria (org.). Políticas Públicas \& Inclusão Digital. Salvador: EDUFBA, 2008. . Inclusão Digital, Software Livre e Globalização contra Hegemônica. In:

(Org.). Software livre e inclusão digital. São Paulo: Editora Conrad, 2003.

SIMÃO FILHO, Adalberto (Coord.). Direito \& Internet - Aspectos Jurídicos Relevantes. São Paulo: Quartier Latin, 2008.

TAKAHASHI, T. (org.). Socinfo: Sociedade da Informação no Brasil: Livro Verde. Brasília: Ministério da Ciência e Tecnologia, 2000.

\section{DOCUMENTOS ELETRÔNICOS}

AVILLA. Mariana Araújo. Relação entre Direito de Informação e Direitos da

Personalidade.Disponível em <http://www.unibrasil.com.br/arquivos/direito/20092/marianaaraujo-cappello-avilla.pdf>. Acesso em 17/01/2012.

BALA, Darlei Gonçalves. Os Limites do Direito de Informação Frente aos Direitos da Personalidade. Jus Navigandi, Teresina, ano 12, n. 1318, 9 fev. 2007. Disponível em: <http://jus.com.br/revista/texto/9477>. Acesso em: 16/01/2012.

BOTELHO, Fernando Neto. A Inclusão Digital e os Direitos Fundamentais. Disponível em <http://www.wirelessbrasil.org/wirelessbr/colaboradores/fernando_botelho/inclusao_e_direito s_04.html>. Acesso em 04/03/2012.

CASTELLS, Manuel. A Difusão da Internet sobre o Conjunto do Planeta Exigirá Forte Ação dos Estados, com Ações Públicas Nacionais e Internacionais. Disponível em:

<http: / /www.jornaldaciencia.org.br/Detalhe.jsp?id=2552>. Acesso em: 29/03/2012.

HARTMANN, Ivar Alberto Martins. O Acesso à Internet como Direito Fundamental. Disponível em: <http://www.biblioteca.idbrasil.gov.br/.../o-acesso-a-internet-como-direito-fundamental>. Acesso em 30/03/2012.

HOESCHL, Hugo César. O Conflito e os Direitos da Vida Digital. Disponível em:

<www.conjur.com.br/2003-mar-16/conflitos_direitos_vida_digital>. Acesso em: 31/03/2012.

MALAQUIAS, Bruno Pires. O Analfabetismo Digital. Disponível em:

<http://www.ibdi.org.br/site/artigos.php?id=159>. Acesso em 25/02/2012. 
ISSN 2316-3054

\section{REDESGD}

EXCLUSÃO E INCLUSÃO DIGITAIS E SEUS REFLEXOS NO EXERCÍCIO DE DIREITOS

Ministério da Ciência e Tecnologia. Livro Verde da Informação no Brasil. Brasília: 2002.

Disponível em: <http://www.mct.gov.br/index.php/content/view/18878.html>. Acesso em $12 / 10 / 2011$.

NASCIMENTO, Jamerson Rogério do. Setor de Telecomunicações: História e Políticas Públicas no Brasil. Disponível em:

<http://www.ibmecrj.br/sub/RJ/files/dissert_mestrado/ADM_jamersonnascimento_nov.pdf >. Acesso em 10/03/2012.

SANTOS, Luiz Alberto dos; CARDOSO, Regina Luna dos Santos. Governo Eletrônico no Brasil: modernização do Estado e políticas para inclusão digital no contexto do ajuste fiscal. Disponível em: <http://portal2.tcu.gov.br/portal/pls/portal/docs/670036.PDF $\geq$ Acesso em: $14 / 03 / 2011$.

SILVA, Gustavo Pamplona. Governo Eletrônico: compras públicas via pregão eletrônico. Jus Navigandi, Teresina, ano 11, n. 1006, 3 abr. 2006. Disponível em:

<http://jus.uol.com.br/revista/texto/8194>. Acesso em: 14/03/2011.

WAGNER, Flávio Rech. - Habilidade e Inclusão Digital - O Papel das Escolas. Disponível em: <http://www.cgi.br/publicacoes/artigos/artigo64.htm>. Acesso em: 31/03/2012. 